\title{
Editorial: Harnessing the past and the present in the service of the future
}

\author{
NinAd R. BondRE ${ }^{1}$ AND Thorsten KIEFER ${ }^{2}$ \\ 'IGBP Secretariat, Royal Swedish Academy of Sciences, Stockholm, Sweden; ninad.bondre@igbp.kva.se \\ 2PAGES International Project Office, Bern, Switzerland
}

I is only in the present that we can study Earth processes as they occur. But sometimes due to a lack of information and sometimes due to an excess of it, we rarely know how those processes will unfold tens or hundreds of years from now. The finitude of the present precludes a comprehensive understanding of all Earth system processes and of the possible scenarios for the future, and it is the past that we must turn to in order to fill in the blanks. Past events are but traces of ancient processes frozen in time, affording us the luxury of knowing how it all ended. The present may very well be the key to the past, but the past represents a future that once was.

One of the achievements of the International Geosphere-Biosphere Programme (IGBP) and its projects has been to facilitate the movement from the present to the past and back to the present so as to build and refine our understanding of global change. As an uncertain future looms large, we rely more than ever on this approach. This issue of the Past Global Changes (PAGES) newsletter features paired perspectives that address the present and the past as two sides of the same coin, seeking to provide a win- dow into the future. The topics cut across the research carried out in IGBP's projects and beyond on land, oceans, the atmosphere and their interfaces. The bringing together of communities, we feel, is timely in the context of the move towards the new Future Earth program by the International Council for Science (ICSU) and its partners.

We came up with a list of topics and one key question per topic after extensive consultation with the PAGES and IGBP communities. The topics do not cover Earthsystem science comprehensively; instead, they reflect the lowest-hanging fruit, i.e. topics where substantial research is carried out on present as well as on past timescales alike. In principle, the article pairs were to address whether and how a particular process or phenomenon would change in the future. In practice, the articles reflect both the diversity of the topics and of the backgrounds and perspectives of the authors. Although dialogues developed between some of the authors of the complementary articles, we did not intentionally attempt to streamline the pairs of articles. This was because we wanted to maintain the duality of the perspectives.
The space restriction to one page for each article by no means allows a comprehensive response to the key questions. But the articles provide different yet complementary takes that also illuminate the questions themselves. There are indications in many articles regarding specific bits of information from the past or the present that could help enhance our process understanding and our projections of the future. Much in the articles remains inchoate, and we have no doubts that the active engagement of our readers will help make them more complete.

The communities studying the past and the present are by no means exclusive, but there can be a tendency for compartmentalization, primarily due to substantially different methods and approaches, but also due to the realities of today's academic environment. By placing side by side the perspectives on the future from the vantage points of the past and the present, we hope to both remind ourselves of the common ends and reaffirm the value of diverse perspectives and collaborations across time scales.



